\title{
Surgical Maze Procedures for Atrial Arrhythmias in Univentricular Hearts, from Maze History to Conversion-Fontan
}

\author{
Charles Kik and Ad J.J.C. Bogers \\ Department of Cardiothoracic Surgery, Thoraxcentre, Erasmus MC
}

The Netherlands

\section{Introduction}

Atrial fibrillation is a common cardiac arrhythmia and occurs in up to $2 \%$ of the general population, but may be present in more than half of the patients late after Fontan surgery for single ventricle physiology (Chugh et al., 2001, Freedom et al., 2003; Steinberg, 2004).

Atrial fibrillation is often considered to be a mild arrhythmia. However, even in patients with a structurally normal heart atrial fibrillation may result in significant symptoms, systemic and pulmonary thrombo-embolism and tachycardia-induced cardiomyopathy leading to a diminished quality of life with increased morbidity and mortality (Ad, 2007).

In patients with a Fontan repair often atrial dilatation occurs and consequently atrial arrhythmias develop that are not only frequent, but easily evolve into life threatening events as well (Ad, 2007).

In general, symptoms of atrial fibrillation are an indication for intervention, the most important being the elevated risk for thrombo-embolism. While pharmaco-medical treatment for atrial fibrillation is aimed at either rate or rhythm control (van Gelder et al., 2002), invasive treatment for atrial fibrillation is aimed at rhythm control. An invasive approach may consist of percutaneous catheter techniques, various surgical approaches or hybrid approaches. With regard to the Fontan circulation, the lateral tunnel has been introduced as primary surgical technique to reduce later atrial enlargement and Fontan constructions with an atrio-pulmonary or atrio-ventricular connection are changed into a Fontan with a lateral tunnel or with an extra-cardiac conduit (Fontan \& Baudet, 1971; de Leval et al., 1998; Mavroudis et al., 1998). This chapter concentrates on surgical maze procedures for atrial fibrillation occurring late after Fontan surgery.

\section{Definitions}

The most widely used classification for atrial fibrillation is published jointly by the American Heart Association, the American College of Cardiology, and the Heart Rhythm Society (American Heart Association, American College of Cardiology \& Heart Rhythm Society, 2002; Cox, 2003). Atrial fibrillation is defined as either paroxysmal, persistent, or permanent. Atrial fibrillation is considered recurrent when two or more episodes have 
occurred. If recurrent atrial fibrillation terminates by itself, it is defined paroxysmal; if not, it is defined persistent. Termination by pharmacologic therapy or electrical cardioversion before expected spontaneous termination does not change the designation of paroxysmal. Permanent atrial fibrillation includes cases of long-standing atrial fibrillation ( $>1$ year), in which cardioversion has not been indicated or has failed to convert the arrhythmia. This terminology applies to episodes of atrial fibrillation that last more than 30 seconds and that are unrelated to a reversible cause.

\section{A history of Fontan constructions}

In patients with one of the many variations of a univentricular heart, surgical palliation can be accomplished to construct a Fontan circulation. In a Fontan circulation essentially the systemic circulation is supported by the single ventricle and all systemic venous return is directed directly to the pulmonary circulation in the absence of a subpulmonary ventricle. At the introduction of the Fontan circulation, the awareness that sinus rhythm was important was already appreciated. However, at that time this was because bradyarrhythmic atrioventricular conduction disturbances turned out to be related to adverse outcome after these procedures (Fontan \& Baudet, 1971). Only in later years, atrial fibrillation was explicitly described in the failing Fontan circulation and attempts at surgical treatment in the conversion-Fontan were initiated (Mavroudis et al., 1998).

\subsection{Implementation of a concept}

The concept of a separated systemic and pulmonary circulation without a subpulmonary ventricle for the palliation of patients with a univentricular heart was first described by Fontan and Baudet (Fontan \& Baudet, 1971). Successful application of this complete right heart bypass was soon confirmed by others (Kreutzer et al., 1973)

The fact that the circulation could be maintained in the absence of the pulmonary ventricle was one of the most important contributions to the field of congenital heart disease and allowed survival of many patients with a univentricular heart into adulthood. However, the original procedures turned out to be not at all free from complications and events at follow up, with early reoperation rates of over 40 percent. Although the basic concept of diverting the systemic venous return directly to the pulmonary circulation is still essential, the Fontan procedure has been extensively modified since its original description, each modification being an attempt to address a specific problem (Davies et al., 2011).

\subsection{Fontan physiology}

The goal of the Fontan procedure was to treat cyanosis. Indeed, the separation of the pulmonary and systemic circulations resulted in improved peripheral oxygen saturation, up to a nearly normal level. However, this was accomplished with a definitely palliative and abnormal hemodynamic arrangement. The most obvious clinical observations included an elevated systemic venous pressure. Combined with intrinsic abnormalities of the single ventricle systolic and diastolic dysfunction can be found. These dysfunctions, together with the obligatory passive circulation of the venous return through the pulmonary vascular bed before filling the systemic ventricle, limit ventricular preload, stroke volume, and ultimately cardiac output. The result is a relative reduction in systemic cardiac output. 
Over the years, it became clear that the success factors for a Fontan circulation are defined by an adequate pulmonary blood flow at an acceptable systemic venous pressures, requiring a low left atrial pressure and a low trans-pulmonary gradient (Hosein et al., 2007). In the absence of a propulsive pump, there is little tolerance for energy loss or inefficiency in the system (Gewillig, 2005).

\subsection{Work in progress}

With the observation that a hypertrophied right atrium was often found in tricuspid atresia and other univentricular hearts, in the early experience of Fontan operations valves were used at various locations in the circuit. The idea was that this right atrial contraction was able to provide some pressure up stream of the implanted valve or valves. In case of a hypoplastic, but approachable right ventricle, this was often incorporated as well. In this regard modifications with valve implants at cavo-atrial level, atrioventricular level (in the situation of a hypoplastic subpulmonary ventricle) and atrio-pulmonary level have been described (Davies et al., 2011; Fontan \& Baudet, 1971; Gewillig, 2005; Kreutzer et al., 1973). The idea of using a valve in the circuit has been abandoned with recognition that it was both unnecessary and potentially deleterious (Davies et al., 2011; Gewillig, 2005)

Over the years also the location of the connection has varied to some extent with constructions having been made with a posterior atrio-pulmonary connection, an anterior atrio-pulmonary connection or inclusion of a hypoplastic right ventricle when this was present. Often in these constructions long term follow up demonstrated dilation of the atrium that was included in the connection from systemic venous return to pulmonary artery. These are the patients who may end up with a failing Fontan involving a dilated right atrium possibly with atrial arrhythmias and atrial fibrillation and with thromboembolic events. For this reason, physicians caring for adult Fontan patients must have the operation notes and be familiar with the variety of circuits and their respective shortcomings.

In order to address this problem, more recently a total cavopulmonary connection is constructed with either an intra-atrial lateral tunnel or completely extra-cardiac prosthetic conduit (Gewillig, 2005; Hosein et al,. 2007; de Leval et al., 1988). Systemic venous blood from the superior vena cava drains directly into the pulmonary arteries. In the intra-atrial lateral tunnel modification, the inferior vena caval blood is routed via an intra-atrial conduit to the caudal side of the pulmonary artery. While a small amount of atrium remains in the circuit to provide growth potential, this atrial tissue is minimized to theoretically reduce the risk of atrial dilatation and arrhythmia. In the extra-cardiac conduit modification, a graft is interposed between the transsected inferior vena cava and the caudal side of the pulmonary artery (Marceletti et al., 1990). The concept for introduction of the extra-cardiac conduit modification was the need to avoid potential pulmonary and systemic venous obstruction in patients with small atrial chambers or malpositioned pulmonary or systemic veins. However, its ease of construction has led many surgeons to adopt it routinely.

As a rigid interposition graft, it shares many of the favourable energetics with the lateral tunnel procedure. However, studies using computational flow dynamics analyses have shown equivalent performance of both the lateral tunnel and extra cardiac conduit Fontan procedures (Bove et al., 2003). In addition, the assumption was made that the extra-cardiac 
conduit modification would be associated with less long-term postoperative arrhythmias; however, to this date no definitive benefit has been proven. Potential drawbacks of the extra-cardiac conduit Fontan modification include the lack of growth potential and the risk of thrombosis of the prosthetic conduit. Despite these concerns, midterm analyses have revealed essentially equivalent outcomes (Kumar et al., 2003).

Usually both modifications are performed as a staged procedure, comprising of neonatal palliation, partial cavopulmonary connection in the first year of life, and completion of total cavo-pulmonary connection in early childhood.

\subsection{The failing Fontan}

Although a Fontan circulation with the nowadays abandoned atrio-pulmonary or atrioventricular connection may have been initially successful, many patients develop complications during long-term follow up in adulthood. These may include systemic ventricular dysfunction, systemic atrio-ventricular valve dysfunction, subaortic obstruction, protein-losing enteropathy, elevated pulmonary vascular resistance, pulmonary arteriovenous malformations and thrombotic circuit events (Davies et al., 2011). In addition this concerns progressive right atrial dilatation and consequently atrial arrhythmias as well, resulting in a loss of atrial transport function and a further decrease of cardiac output in these patients.

Arrhythmias in these patients with a Fontan circulation are regarded to be the result of combination of atrial dilation, extensive atrial suture lines and cardiac dysfunction ion (Peters \& Somerville, 1992). Percutaneous treatment of these arrhythmias is often limited by inability to access the appropriate cardiac chamber and has had only variable success (Walsh, 2007).

In an attempt to offer a further treatment to patients facing these problems, the total cavopulmonary connection, either with a lateral intra-atrial tunnel or with an extra-cardiac conduit, is also being applied as a conversion for the failing atrio-pulmonary or atrioventricular connection including a surgical maze procedure to treat the atrial arrhythmias (Mavroudis et al., 1998).

\section{A history of maze surgery for atrial fibrillation}

Maze surgery for atrial arrhythmias is characterised by a stepwise development in pioneering during the early years. Some of the present surgical procedures are being used based on limited experience and technical feasibility rather than true science (Ad 2007).

\subsection{Left atrial isolation}

In 1980, a left atrial isolation procedure was described, with confinement of atrial fibrillation to the left atrium (Ad, 2007). The right atrium and both of the ventricles continued to be in a synchronized sinus rhythm. This procedure was relatively effective in restoring regular ventricular rhythm without the need for a permanent pacemaker. This procedure also restored normal cardiac hemodynamics in patients with normal left ventricular function. The normalized right-sided cardiac output apparently was passed to the left atrium functioning as a conduit to the left ventricle. Unfortunately, the risk for systemic thrombo- 
embolism was unaffected because the left atrium stayed in fibrillation. Further steps in maze surgery for atrial fibrillation ideally needed to realise not only abolishing atrial fibrillation, but also re-establishing sinus rhythm, maintaining atrio-ventricular synchrony, restoring normal atrial transport function, and eliminating the risk of thrombo-embolic events.

\subsection{Cox-maze procedure}

The concept of the Cox-maze procedure resulted from animal studies by Cox et al. (Boineau et al., 1980; Cox et al., 1991a; Smith et al., 1985). The animal experiments suggested that a mechanism for atrial fibrillation could be found in large macro- re-entrant circuits around the orifice of the left atrial appendage and the ostia of the four pulmonary veins (Smith et al., 1985). Based on these findings, the atrial transsection procedure was introduced, consisting of an incision dorsally in the atria from the annulus of the tricuspid valve to the annulus of the mitral valve. By combining computerized mapping data in humans and data recorded in animal models, a better picture of the mechanisms of both atrial flutter and fibrillation evolved (Canavan et al., 1988; Cox et al., 1991a; Smith et al., 1985). It was documented that both in atrial flutter and fibrillation, three components could be identified: macro re-entrant circuit(s), passive atrial conduction in the atrium not involved in the macro re-entrant circuit(s), and atrioventricular conduction. The electrophysiological characteristics of these three components define a spectrum of atrial arrhythmias, from simple atrial flutter to complex atrial fibrillation. A surgical procedure capable of interrupting all macro reentrant circuits that might potentially develop in the atria was developed. The procedure was designed to allow the sinus node to resume activity following surgery and to propagate the sinus impulse through both atria, and was first applied clinically in 1987 (Canavan et al., 1988; Cox et al., 1991a, Cox, 2011). This Cox-maze I procedure was associated with the late incidence of the inability to generate an appropriate sinus tachycardia in response to exercise, and with left atrial dysfunction. In order to deal with these drawbacks, the procedure was modified in steps to the Cox-maze III procedure (Cox, 1991; Cox et al., 1991b; Cox et al., 1995a; Cox et al., 1995b).

\subsection{Cox-maze III}

The Cox-maze III procedure was associated with a higher incidence of sinus rhythm, with improved long-term sinus node function, with fewer pacemaker implantations, and with improved long-term atrial transport function. In addition, the Cox-maze III procedure was technically somewhat less demanding than earlier procedures (Arcidi et al., 2000; Kosekai, 2000; McCarthy et al.,2000; Schaff et al., 2000). The Cox-maze III procedure proved to be effective in treating atrial fibrillation (Arcidi et al., 2000; Cox et al., 1996; Kosekai, 2000; McCarthy et al.,2000; Schaff et al., 2000).

Despite its success, the procedure has not been widely adopted, in part owing to its remaining complexity and technical difficulty. There was also a relatively high incidence of morbidity associated with the procedure, such as re-exploration for bleeding and a $10 \%$ incidence of pacemaker implantation. Because of the technical complexity of the original cut-and-sew Cox-maze procedure, it required a formal median sternotomy and cardiopulmonary bypass (Cox, 1991; Cox et al., 1996). As a result, only a few surgeons started to perform the procedure and gained sufficient experience, and many were waiting for less-invasive or simpler approaches to treat this extremely common arrhythmia. 


\subsection{Maze modifications}

Over the years, a better understanding regarding atrial fibrillation pathophysiology evolved. In 1998, Haissaguerre and associates published a key work describing the pattern of the arrhythmogenic-foci-originating atrial fibrillation (Haissaguerre et al., 1998). In patients with paroxysmal atrial fibrillation, the pulmonary veins were found to be an important source of triggers initiating paroxysmal atrial fibrillation, which would probably respond to treatment with radiofrequency ablation. Based on these findings, a new strategy for non-pharmacological treatment was developed involving pulmonary vein isolation. However, some patients exhibit a much more complex pattern of initiation and maintenance of the arrhythmia, and the solution in certain cases is not as simple as pulmonary vein isolation only ( Nademanee et al, 2004; Schmitt et al., 2002).

In the late 1990s, the first few cases of cryomaze procedure were performed. These were mainly application of cryoablation lines. The objective of the cryoablation was to replace the surgical incisions with transmural ablation lines to create conduction block. In 1999, the first non-cut-and-sew full Cox-maze procedure was performed using cryothermal energy as the only ablation modality. It was later that year that the Cox-maze III procedure was modified to what was later referred as the Cox-Maze IV. In this procedure, the pulmonary veins were isolated bilaterally and a connecting lesion was applied rather than performing the original box lesion. This modification was based on the findings of Haissaguerre and associates (Haissaguerre et al., 1998). The cryosurgical Cox-Maze procedure was also performed as a minimally invasive procedure through a right anterior thoracotomy (Cox \&Ad, 2000). Most of the subsequent surgical modifications to the original Cox-Maze procedure were based on new surgical ablation devices, utilizing various ablative technologies. The new devices facilitated new surgical procedures to treat atrial fibrillation using different ablation protocols. Currently, it is a common approach to replace the surgical incisions with linear lines of ablation. Various ablation devices have been developed using different energy sources to perform the ablation, including radiofrequency (unipolar and bipolar) (Khargi et al., 2001; Gillinov et al., 2005), microwave (Kabbani et al., 2005), laser (Garrido et al., 2004), cryo-ablation Mack et al., 2009), and high-frequency ultrasound (Ninet et al., 2005). The concept behind these new technologies was to replace the surgical incisions with lines of transmural ablation creating conduction blocks. By using the ablation devices properly, the goal of the maze procedure to block re-entrant circuits can be maintained. However, various publications revealed that the various lesions applied on the heart under different conditions may result in non-transmural lesions (Damiano, 2003; Viola et al., 2002). Theoretically, the cut-and-sew Cox-maze procedure can be replaced by a more simple technique that is much less demanding technically and may be performed using less invasive tools.

\subsection{Current surgical strategies}

At present, a number of surgical approaches and procedures are described and being practised. Different options regarding surgical procedures are available (Ad, 2007). While the Cox-maze procedures were the product of a stepwise process, some of the present surgical procedures have only been based on limited experience and technical feasibility rather than true science (Ad, 2007). Some of the issues still under debate are, whether or not the maze procedure can be confined to the left atrium or to pulmonary vein isolation or that 
bi-atrial procedures are indicated, whether or not cardiopulmonary bypass is to be applied and which route of exposure facilitates an optimal result.

Although it was previously thought that atrial fibrillation was maintained by multiple macro-reentrant circuits, there is evidence that focal triggers can be responsible for the initiation of paroxysmal atrial fibrillation as well (Hocini et al., 2000; Nademannee et al., 2004). Therefore, preoperative electrophysiological diagnostic studies into areas of early activation, may allow surgeons to identify the particular triggers of atrial fibrillation in individual patients. Unfortunately, the analysis of multiple atrial electrocardiograms over long periods of time has been difficult. Thus, it usually is not possible to locate the precise focal point of origin responsible for the initiation or maintenance of AF in the majority of patients.

Nevertheless, modern atrial fibrillation surgery should include different surgical approaches to match the procedure to a given patient. Currently, surgery through a median sternotomy is being offered to patients with atrial fibrillation who are candidates for a concomitant cardiac surgical procedure. It is also be applied in patients who are candidates for an isolated maze procedure and who are at high risk for a minimally invasive approach. Generally, these patients should undergo a full biatrial maze lesion set. There is no place for the cut-and-sew technique anymore unless surgical ablation devices are not available. Any device that satisfies the operator in creating reliable transmural lesions can be used. Surgeons should be familiar with the limitations of each device.

In an effort to reduce cardiopulmonary bypass and cross clamp time, parts of the operation can be performed off bypass and before or after cross-clamping of the aorta. Right-sided lesions can be performed in every case before the patient is connected to cardiopulmonary bypass. One way of doing this is based on applying three purse-strings to the right atrial wall through which the ablation device can be introduced.

With left-sided lesions, there are two possible methods. The first is using the classical box lesion around all four pulmonary veins, as described in the original Cox-maze procedure. An endocardial approach for this lesion is usually performed in redo cases in which dissection of the epicardial adhesions around the pulmonary vein may be difficult. The other option is to encircle the right and left pulmonary veins from the epicardial side. This can be done off-bypass in some cases and with the support of cardiopulmonary bypass but without cross-clamping in others. Following isolation of the pulmonary veins and the necessary steps, the left atrium is opened and a connecting lesion and a mitral valve isthmus lesion to include the coronary sinus are created.

A minimally maze procedure through right anterior mini-thoracotomy can be performed for an isolated maze procedure or be combined with other procedures through the same approach [Garrido et al., 2004; Saltman et al., 2003]. The minimally invasive approach can also be considered in redo surgery, especially when a repeat median sternotomy may carry an increased risk. The procedure involves groin cannulation to connect the patients to cardiopulmonary bypass. The right sided lesions can be performed on a beating heart with or without cardiopulmonary support. Following cross-clamping, a vertical left atriotomy is performed, and the left sided lesions are made, creating a box lesion around all the pulmonary veins and a connecting lesion to the left atrial appendage and to the mitral valve isthmus with special attention to the coronary sinus. In the original technique, the left atrial 
appendage is resected, but increasingly the left atrial appendage orifice is oversewn from the endocardial side. Mitral valve procedures should be performed only after completion of the Cox-Maze procedure to ensure perfect left atrial isthmus ablation. In case of tricuspid valve surgery and repair of an atrial septal defect, double venous cannulation is required and the right atrium is opened, so the purse-string approach cannot be applied. When performed properly, the results obtained from the minimally invasive procedure are good (Ad, 2007).

Surgery to achieve pulmonary vein isolation only with or without left atrial appendage is now being performed and can be done as a totally endoscopic procedure using different ablation devices (Kabbani et al 2005; Saltman et al. 2003). Bilateral limited thoracotomies or mini sternotomy can also be used to control and isolate the pulmonary veins (Kawaguchi et al., 1996; Ninet et al., 2005). The major advantage of this approach is that it can be performed without the use of cardiopulmonary bypass, and in most instances, pulmonary vein isolation and left atrial appendage disarticulation can be offered. The experience gathered with this approach is fairly limited, and the follow-up in most reports is fairly short in a highly selected group of patients. It is clear that pulmonary vein isolation is not as successful in patients with more complex atrial fibrillation, such as permanent atrial fibrillation and enlarged left atrium, as in patients with paroxysmal atrial fibrillation (Hocini et al., 2000).

\subsection{Prospects}

Maze procedures are not guided by electrophysiological mapping and thus theoretically include some unnecessary lesions for some patients. Recent data has suggested that in some patients, there is a potential to cure their arrhythmia by performing procedures that are confined to the left atrium or include only isolation of the pulmonary veins (Nadamanee et al., 2004; Wolf et al., 2005). However, the success rate for these limited procedures is in general less than optimal (Barnett \& Ad, 2006). Epicardial mapping systems may be developed that support the understanding of the pathophysiology of the arrhythmia and can be used to guide the surgeon to choose the appropriate procedure. Map-guided surgery has a great deal of potential; however, mapping patients in atrial fibrillation is complex, and the current intra-operative mapping devices would have to be minimized to allow minimally invasive surgery (Nitta et al., 2003).

\section{Maze application in conversion-Fontan}

When localised anatomic problems are associated with deteriorisation of a patient with a Fontan circulation, treatment (either surgical or interventional) should be considered. Recently, the total cavo-pulmonary connection, either with a lateral intra-atrial tunnel or with an extra-cardiac conduit, is also being applied as a conversion for the failing atriopulmonary connection or atrio-ventricular connection (Mavroudis et al., 1998). The combination of revision of the intracardiac form of Fontan to either a lateral tunnel or an extra-cardiac conduit, with an atrial reduction procedure, an appropriately modified maze procedure (see Figures 1 and 2) and the possibility of dual chamber pacing has been successful in a number of patients. It should be clear that following Fontan conversion morbidity is considerable and that mortality (up to 10\%) is not insignificant, but those results continue to improve (Mavroudis et al., 2007). It should also be clear that an important number of Fontan failure patients are not amenable to revision or conversion. 


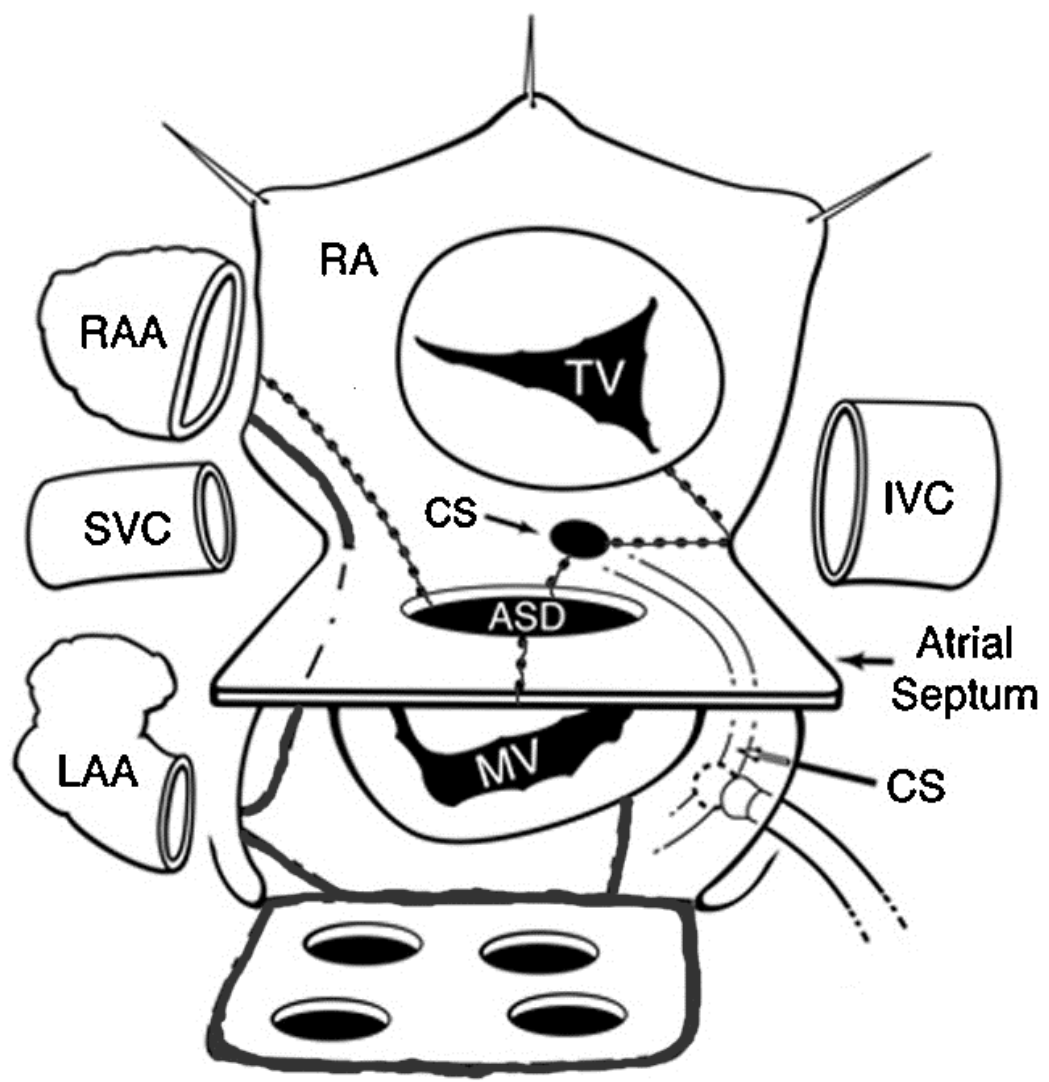

On the right side, the right atrial appendage (RAA) is amputated and the inferior caval vein (IVC) and superior caval vein (SVC) are transsected in connection with the right atriotomy. On the left side, the left atrial appendage (LAA) is amputated. With cryoablation, the right-sided lines from atrial septal defect (ASD) to the RAA, to the coronary sinus (CS) and through the crista terminalis to the posterior cut edge of the atrial wall and from the IVC to the CS and to the tricuspid valve annulus (TV) are made. The left-sided cryoablation lines consisted of lines from the pulmonary venous encircling to the LAA, to the mitral valve annulus (MV) and the CS cryoablation. In addition, a line from the base of the RAA to the base of the LAA across the domes of the right and left atria for the left atrial maze procedure was cryo-ablated.

Fig. 1. Diagram with atrial view from the right side of a modified right-sided maze procedure for right atrial re-entry tachycardia (continuous dotted lines) and a left atrial maze procedure for atrial fibrillation and left atrial re-entry tachycardia (continuous lines) (Adapted from Mavroudis et al., 2008).

At conversion, the atrial arrhythmias are in addition being treated by excision of a greater part of the dilated right atrial free wall and by intra-operative additional ablation of potential circuits of atrial arrhythmias. Intra-operative ablation consists of a right-sided maze operation for atrial flutter or the Cox-III maze operation for atrial fibrillation (Backer et al., 2006). 


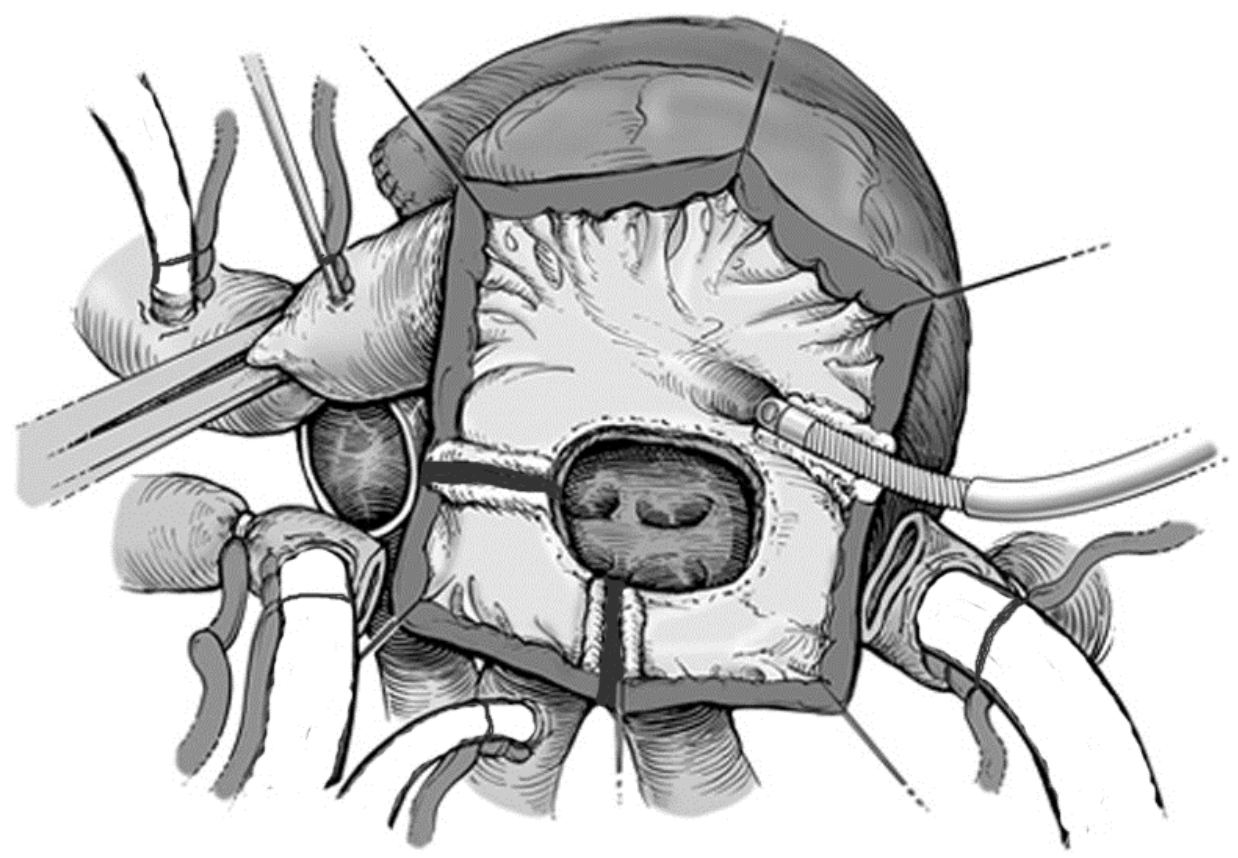

The inferior and superior venae cavae have been transected, the atrial wall excision has been performed, and the atrial septal patch has been removed. The right atrial appendage (when still present) is amputated. If the sino-atrial node is nonfunctional, no specific measures are taken for preservation of this structure. Cryoablation lesions are placed in three areas to complete the modified right-sided maze procedure. Cryoablation lesions are made to connect the superior portion of the atrial septal ridge with the incised area of the right atrial appendage and to connect the posterior portion of the atrial septal ridge with the posterior cut edge of the atrial wall, which extends through the crista terminalis. For the isthmus ablation, the lines are dependent on the anatomic substrate. In patients with tricuspid atresia, as noted here, the cryoablation lesion is placed to connect the postero-inferior portion of the coronary sinus orifice with the transected inferior vena cava.

In other anomalies, the isthmus block is completed by an additional line to connect the tricuspid valve annulus or common atrioventricular valve annulus with the transected inferior vena cava orifice.

Fig. 2. Atrial view from the right side of a patient who had an atrio-pulmonary Fontan procedure after aortic cross-clamping and cardioplegic arrest (Adapted from Mavroudis et al., 2008).

In addition, some authors propagate completion of surgery with an epicardial pacemaker system for further management of arrhythmias (Backer et al., 2006). The rationale is that transvenous access to the heart is not possible anymore and that frequently conversion concerns a more than once repeated sternotomy.

After conversion to a total cavo-pulmonary connection, most patients improve in New York Heart Association class (Backer et al., 2006; Bogers et al., 2008). This improvement may, however, take up to a year after surgery. Without anti-arrhythmic surgery, the recurrence rate of atrial arrhythmias is reported to be up to $76 \%$ (Backer et al., 2006). Among patients 
with a form of intracardiac Fontan and atrial dysrhythmias, conversion to an extra-cardiac conduit with a modified atrial maze procedure results in approximately $80 \%$ freedom from recurrence at 5 years of follow up (Deal et al., 2007). Moreover, recovery of atrial transport function, which is essential in the Fontan circulation, can be accomplished (Bogers et al., 2008)

\section{Factors affecting the results of surgical maze procedures for atrial fibrillation}

Taken into account that the different surgical strategies are usually the product of evolving techniques, the results from different series are in general not easy to accumulate or to compare, but results are fairly rewarding, not only with regard to restoring sinus rhythm, but also with regard to freedom of stroke and freedom of cardiovascular-related death on midterm follow up ( Ad et al., 2000; Ballaux et al., 2006; Bando et al ., 2002, 2003; Cox et al., 1995a; Damiano et al., 2003; Fujita et al.,2010, Gaynor et al., 2007; Gillinov et al., 2007; Kim et al., 2007; Mokadam et al., 2004; Prasad et al., 2003; Rahman et al., 2010). In addition, differences in the reported success rate in restoring sinus rhythm are a continuing debate among cardiac surgeons and cardiologists on the outcome of maze procedures, because surgeons more often treat patients with chronic atrial fibrillation, while cardiologists choose more often to treat patients with paroxysmal atrial fibrillation.

The long-term success of maze procedures is limited in patients with well established predictors for failure. Arrhythmia duration prior to the procedure was found to be a predictor of failure. This may be related to a more significant adverse atrial tissue remodelling, resulting in extensive fibrosis and disparity of the action potential as well as enlargement of the left atrium. Increased size of the left or single atrium is also a powerful predictor for late failure, particularly in an atrium greater than $6 \mathrm{~cm}$ in diameter [Gaynor et al., 2005; Gillinov et al., 2006; Kawaguchi et al., 1996]. Increased age at the time of the procedure is another predictor for late failure, although not reported as such in all series (Damiano et al., 2003; Rahman et al., 2010). Other clinical variables that have been mentioned as having a negative impact on late success, such as structural heart disease, rheumatic heart disease, and the type of the atrial fibrillation, have not been consistently found by all centres to be significant (Ad, 2007). For these factors, the influence on outcome after maze surgery in conversion-Fontan is unknown.

Many problems encountered when the Cox-maze procedure was first developed are now being repeated in patients undergoing these less complex procedures. Therefore, in general a better classification of candidates for the procedure may enhance our understanding of the pathophysiology of atrial fibrillation and improve results of the modified procedures. This holds as well for congenital heart disease in general as well as for univentricular hearts after a Fontan palliation.

Before applying a maze procedure, a few variables should be discussed and investigated for their possible impact on the results of the surgical treatment in a certain patient. Important issues in this regard are: the type of atrial fibrillation, the duration in time of atrial fibrillation, the size of the left and right atria or single atrium, the presence of additional heart diseases (by definition in univentricular hearts), the procedure intended for curing atrial fibrillation, the treatment of atrial fibrillation in a combined procedure in which 
cardiopulmonary bypass is used (by definition in conversion-Fontan), the presence of clots in the left or single atrial appendage or a patent foramen ovale, limiting in general the ability to perform a procedure without cardio-pulmonary bypass.

Probably only a limited percentage of patients with lone atrial fibrillation will ever become candidates for the classical open-heart maze procedures (Ad, 2007). However, a number of device-based ablation procedures are being performed, which are less complex and technically less demanding in those patients. Therefore, the discussion concerning the complexity of the maze procedure should be shifted towards application with decision trees regarding specific maze procedures for specific clinical questions (such as the conversionFontan), e.g. type of maze procedure, timing of the maze procedure, type of equipment and energy source. The continuing effort to relieve the invasive downside of surgical maze procedures is warranted but with caution and without compromising the success rate (Ad, 2007). Surgery for atrial fibrillation should involve a true decision-making process, just as with any other surgical procedure. Therefore, combining all these variables and understanding the importance of each one of them may lead to a higher success rate, also in surgery for congenital heart disease.

\section{Conclusion}

Atrial fibrillation may result in significant symptoms in patients with a structurally normal heart, and in patients with a univentricular circulation atrial fibrillation can be deleterious. Nowadays symptomatic atrial fibrillation can be treated with catheter-based ablation, surgical ablation or hybrid approaches. On top of this maze experience, surgical ablation for atrial arrhythmias at conversion of atrio-pulmonary or ventriculo-pulmonary Fontan to a total cavopulmonary connection is feasible with recovery of both sinus rhythm as well as atrial transport function.

\section{References}

Ad N (2007) The Cox-maze procedure: history, results and predictors for failure. J Interv Card Electrophysiol 20:65-71

Ad N, Cox JL, Palazzo T., Kim YD, Syderhoud JP, Degroot KW, et al. (2000) Stroke prevention as an indication for the Maze procedure in the treatment of atrial fibrillation. Seminars Thorac Cardiovasc Surg 12:56-62

American College of Cardiology, American Heart Association, European Society of Cardiology (2002) Pocket Guidelines for the Management of Patients with Atrial Fibrillation

Arcidi JM Jr, Doty DB, Millar RC (2000) The Maze procedure: the LDS Hospital experience. Seminars Thorac Cardiovasc Surg 12:38-43

Backer CL, Deal BJ, Mavroudis C, Franklin WH, Stewart RD (2006) Conversion of the failedFontan circulation. Cardiol Young 16(suppl 1):85-91

Ballaux PKEW, Geuzebroek GSC, van Hemel NM, Kelder JC, Dossche KME, Ernst JMPG, et. al. (2006) Freedom from atrial arrhythmias after classic maze III surgery: A 10-year experience. J Thorac Cardiovasc Surg 132:1433-1440 
Bando K, Kobayashi J, Hirata M, et al. (2003) Early and late stroke after mitral valve replacement with a mechanical prosthesis: Risk factor analysis of a 24-year experience. J Thorac Cardiovasc Surg 126:358-364

Bando K, Kobayashi J, Sasako Y, Tagusari O, Niwaya K, Kitamura S (2002) Effect of maze procedure in patients with atrial fibrillation undergoing valve replacement. J Heart Valve Dis 11:719-724

Barnett SD, Ad N (2006) Surgical ablation as treatment for the elimination of atrial fibrillation: A meta-analysis. J Thorac Cardiovasc Surg 131:1029-1035

Bogers AJJC, Kik C, de Jong PL, Meijboom FJ (2008). Recovery of atrial transport function after a maze procedure for atrial fibrillation in conversion of a failing Fontan circulation. Neth Heart J 16:170-172

Boineau JP, Schuessler RB, Mooney C, et al. (1980) Natural and evoked atrial flutter due to circus movement in dogs. Am J Cardiol 45,1167-1181

Bove EL, de Leval MR, Migliavacca F, Guadagni G, Dubini S (2003) Computational fluiddynamics in the evaluation of hemodynamic performance of cavopulmonary connections after the Norwood procedure for hypoplastic left heart syndrome, J Thorac Cardiovasc Surg 126:1040-1047.

Canavan TE, Schuessler RB, Cain ME, et al. (1998) Computerized global electrophysiological mapping of the atrium in a patient with multiple supraventricular arrhythmias. Ann Thorac Surg 46,223-231

Chugh SS, Blackshear JL, Shen WK, et al (2001). Epidemiology and natural history of atrial fibrillation: Clinical implications. J Am Coll Cardiol 37:371-378

Cox JL (1991) The surgical treatment of atrial fibrillation. IV. Surgical technique. J Thorac Cardiovasc Surg 101,584-592

Cox JL (2003) Atrial fibrillation I: A new classification system. J Thorac Cardiovasc Surg 126:1686-1692

Cox JL (2011) The first maze procedure. J Thorac Cardiovasc Surg 141:1093-1097

Cox JL, Ad N (2000) New surgical and catheter-based modifications of the Maze procedure. Seminars Thorac Cardiovasc Surg 12:68-73

Cox JL, Boineau J P, Schuessler RB, et al. (1995) Modifications of the Maze procedure for atrial flutter and atrial fibrillation. I. Rationale and surgical results. J Thorac Cardiovasc Surg 110:473-483

Cox JL, Canavan TE, Schuessler RB, et al. (1991a)The surgical treatment of atrial fibrillation. II. Intraoperative electrophysiologic mapping and description of the electrophysiologic basis of atrial flutter and atrial fibrillation. J Thorac Cardiovasc Surg 101, 406-426

Cox JL, Jaquiss RD, Schuessler RB, et al. (1995) Modifications of the Maze procedure for atrial flutter and atrial fibrillation. II. Surgical technique of the Maze III procedure. J Thorac Cardiovasc Surg 110,485-495

Cox JL, Schuessler RB, D'Agostino HJ J et al. (1991) The surgical treatment of atrial fibrillation: III Development of a definite surgical procedure. J Thorac Cardiovasc Surg 101, 569-583

Cox JL, Schuessler RB, Lappas DG, et al. (1996) An 8.5 year clinical experience with surgery for atrial fibrillation. Ann Surg 224,267-275

Damiano RJ Jr (2003) Alternative energy sources for atrial ablation: judging the newtechnology. Ann Thorac Surg 75:329-330 
Damiano RJ Jr, Gaynor S., Bailey M, Prasad S, Cox J., Boineau J., et al. (2003) The long-term outcome of patients with coronary disease and atrial fibrillation undergoing the Cox maze procedure. J Thorac Cardiovasc Surg 126:2016-2021

Davies RR, Chen JM, Mosca R (2011) The Fontan procedure: evolution in technique; attendant imperfections and transplantation for "failure". Seminars Thorac Cardiovascular Surg 14:55-66

de Leval MR, Kilner P, Gewillig M, Bull C (1988) Total cavopulmonary connection: a logical alternative to atriopulmonary connection for Fontan operations. Experimental studies and early clinical experience. J Thorac Cardiovasc Surg 96:682-695

Deal BJ, Mavroudis C, Backer CL (2007) Arrhythmia management in the Fontan patient. Pediatr Cardiol 28:448-456.

Fontan F, Baudet E (1971) Surgical repair of tricuspid atresia. Thorax 26:240-248 Freedom RM, Li J, Yoo S.J (2003). Late complications following the Fontan operation. In: Diagnosis and management of adult congenital heart disease, Gatzoulis MA, Webb GD, Daubeney PEF (Eds.), pp. 85-92, Edinburgh, Churchill Livingstone, Edinburgh Fujita T, Kobayashi J, Toda K, Nakajima H, Iba Y, Shimahara Y, Yagihara T (2010) Long-term outcome of combined valve repair and maze procedure for nonrheumatic mitral regurgitation. J Thorac Cardiovasc Surg 140:1332-1337

Garrido MJ, Williams M, Argenziano M (2004) Minimally invasive surgery for atrial fibrillation: toward a totally endoscopic, beating heart approach. J Cardiac Surg 19:216-220

Gaynor SL, Schuessler RB, Bailey MS, Ishii Y, Boineau JP, Gleva MJ, et al. (2005) Surgical treatment of atrial fibrillation: predictors of late recurrence. J Thorac Cardiovasc Surg 129:104-111

Gewillig M (2005) The Fontan circulation. Heart 91:839-846

Gillinov AM, Bhavani S, Blackstone EH, Rajeswaran J, Svensson LG, Navia JL, et al. (2006) Atrial fibrillation: impact of patient factors and lesion set. Ann Thorac Surg 82:502513

Gillinov AM, McCarthy PM, Blackstone EH, Rajeswaran J, Pettersson G, Sabik JF, et al. (2005) Surgical ablation of atrial fibrillation with bipolar radiofrequency as the primary modality. J Thorac Cardiovasc Surg 129:1322-1329

Haissaguerre M, Jais P, Shah DC, Takahashi A, Hocini M, Quiniou G, et al. (1998) Spontaneous initiation of atrial fibrillation by ectopic beats originating in the pulmonary veins. New Eng J Med 339:659-666

Hocini M, Haissaguerre M, Shah D, et al. (2000) Multiple sources initiating atrial fibrillation from a single pulmonary vein identified by a circumferential catheter. Pacing Clin Electrophysiol 23:1828-31

Hosein RB, Clarke AJ, McGuirk SP, griselli M, Stumper O, de Giovanni JV, barron DJ, BrawnWJ (2007) Factors influencing early and late outcome following the Fontan procedure in the current era: The 'two commandments'?, Eur J Cardiothorac Surg 31:344-352.

Kabbani SS, Murad G, Jamil H, Sabbagh A, Hamzeh K (2005) Ablation of atrial fibrillationusing microwave energy-early experience. Asian Cardiovasc Thorac Ann 13:247-250 
Kawaguchi AT, Kosakai Y, Isobe F, Sasako Y, Eishi K, Nakano K, et al. (1996) Factors affecting rhythm after the maze procedure for atrial fibrillation. Circulation $94(9$ Suppl):II139-II14

Khargi K, Deneke T, Haardt H, Lemke B, Grewe P, Muller KM, et al. (2001) Saline-irrigated, cooled-tip radiofrequency ablation is an effective technique to perform the maze procedure. Ann Thorac Surg 72:S1090-S1095

Kim KC, Cho KR, Kim YJ, Sohn DW, Kim KB (2007) Long-term results of the Cox-Maze III procedure for persistent atrial fibrillation associated with rheumatic mitral valve disease: 10-year experience. Eur J Cardio-Thorac Surg 31:261-266

Kosakai, Y (2000) Treatment of atrial fibrillation using the Maze procedure: the Japanese experience. Seminars Thorac Cardiovasc Surg 12:44-52

Kreutzer G, Galindez E, Bono H, de Palma C, Laura JP (1973) An operation for the correction of tricuspid atresia, J Thorac Cardiovasc Surg 66: 613-621

Kumar SP, Rubinstein CS, Simsic JM, Taylor AB, Saul JP, Bradley SM (2003) Lateral tunnel versus extracardiac conduit Fontan procedure: a concurrent comparison. Ann Thorac Surg 76:1389-1396

Mack CA, Milla F, Ko W, Girardi LN, Lee LY, Tortolani A, et al. (2009) Surgical treatment of atrial fibrillation using argon-based cryoablation during concomitant cardiac procedures. Circulation 112(9 Suppl):I1-I6

Marcelletti C, Corno A, Giannico S, Marini B (1990) Inferior vena cava-pulmonary artery extracardiac conduit: a new form of right heart bypass. J Thorac Cardiovasc Surg 100:228-232

Mavroudis C, Backer CL, Deal BJ, Johnsrude CL (1998) Fontan conversion to cavopulmonary connection and arrhytmhia circuit cryoablation. J Thorac Cardiovasc Surg 115:547-556

Mavroudis C, Deal BJ, Backer CL, Stewart RD, Franklin WH, Tsao S, Ward K. DeFreitas RA (2007) J Maxwell Chamberlain Memorial Paper for congenital heart surgery. 111 Fontan conversions with arrhythmia surgery: surgical lessons and outcomes. Ann Thorac Surg 84:1457-1465.

Mavroudis C, Backer CL, Deal BJ (2008) Late reoperations for Fontan patients: state of theart invited review. Eur J Cardiothorac Surg 34:1034-40

McCarthy PM, Gillinov AM, Castle L, Chung M, Cosgrove D III (2000) The Cox-Maze procedure: the Cleveland Clinic experience. Seminars Thorac Cardiovasc Surg 12:25-29

Mokadam NA, McCarthy PM, Gillinov AM, et al. (2004) A prospective multicenter trial of bipolar radiofrequency ablation for atrial fibrillation: Early results. Ann Thorac Surg 78:1665-1670

Nademanee K, McKenzie J, Kosar E, et al. (2004) A new approach for catheter ablation of atrial fibrillation: mapping of the electrophysiologic substrate. J Am Coll Cardiol 2004;43:2044-2053

Ninet J, Roques X, Seitelberger R, Deville C, Pomar JL, Robin J, et al. (2005) Surgical ablation of atrial fibrillation with off-pump, epicardial, high-intensity focused ultrasound: Results of a multicenter trial. J Thorac Cardiovasc Surg 130:803-809

Nitta T, Ohmori H, Sakamoto S, Miyag, Y, Kanno S, Shimizu K (2003) Map-guided surgeryfor atrial fibrillation. J Thorac Cardiovasc Surg 129:291-299 
Peters NS, Somerville J (1992) Arrhythmias after the Fontan procedure. Br Heart J 68:199204

Prasad SM, Maniar HS, Camillo CJ, Schuessler RB, Boineau JP, Sundt TM III, et al. (2003) The Cox maze III procedure for atrial fibrillation: long-term efficacy in patientsundergoing lone versus concomitant procedures. J Thorac Cardiovasc Surg 126:1822-1828

Rahman NM, Chard RB, Thomas SP (2010) Outcomes for surgical treatment of atrial fibrillation using cryoablation during concomitant procedures. Ann Thorac Surg 90:1523-8

Saltman AE, Rosenthal LS, Francalancia NA, Lahey S (2003) A completely endoscopic approach to microwave ablation for atrial fibrillation. Heart Surg Forum 6:E38- E41

Schaff HV, Dearani JA, Daly RC, Orszulak TA, Danielson GK (2000). Cox-Maze procedure for atrial fibrillation: Mayo Clinic experience. Seminars Thorac Cardiovasc Surg 2000;12:30-37

Schmitt C, Ndrepepa G, Weber S, Schmieder S, Weyerbrock S, Schneider M, et al. (2002)Biatrial multisite mapping of atrial premature complexes triggering onset of atrial fibrillation. Am J Cardiol 89:1381-1387

Smith PK., Holman WL, Cox JL (1985) Surgical treatment of supraventricular tachyarrhythmias. Surgical Clinics North America 65,553-570

Steinberg JS: Atrial fibrillation: an emerging epidemic? Heart 2004; 90:239-240

van Gelder IC, Hagens VE, Bosker HA, et al. (2002) A comparison of rate control and rhythm control in patients with recurrent persistent atrial fibrillation. N Engl J Med 347:1834-1840

Viola N, Williams M, Oz MC (2002) The technology in use for the surgical ablation of atrial fibrillation. Seminars Thorac Cardiovasc Surg 14:198-205

Walsh EP (2007) Interventional electrophysiology in patients with congenital heart disease. Circulation 115:3224-3234

Wolf RK, Schneeberger EW, Osterday R, Miller D, Merrill W, Flege JB Jr, et al. (2005) Videoassisted bilateral pulmonary vein isolation and left atrial appendage exclusion for atrial fibrillation. J Thorac Cardiovasc Surg 130:797-802 


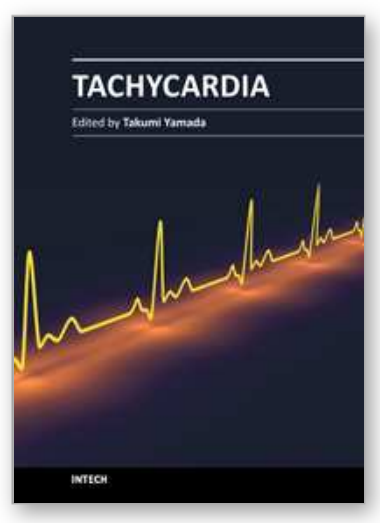

\author{
Tachycardia \\ Edited by Prof. Takumi Yamada
}

ISBN 978-953-51-0413-1

Hard cover, 202 pages

Publisher InTech

Published online 30, March, 2012

Published in print edition March, 2012

Heart rates are normally controlled by a natural pacemaker, the sinus node, and normal heart rhythm is called sinus rhythm. Tachycardia is defined as a faster heart rhythm than normal sinus rhythm. Tachycardias can cause symptoms such as palpitations, chest pain, shortness of breath and fatigue, which reduce the quality of life. Fast tachycardias can cause hemodynamic collapse and sudden cardiac death. The causes, mechanisms, and origins of tachycardias are various. The diagnosis of tachycardias is made by electrocardiograms and electrophysiological testing. Tachycardias can be managed and treated by pharmacological and nonpharmacological approaches. This book covers these concerns from basic and clinical points of view and will lead to a further understanding and improvement in the clinical outcomes of tachycardias.

\title{
How to reference
}

In order to correctly reference this scholarly work, feel free to copy and paste the following:

Charles Kik and Ad J.J.C. Bogers (2012). Surgical Maze Procedures for Atrial Arrhythmias in Univentricular Hearts, from Maze History to Conversion-Fontan, Tachycardia, Prof. Takumi Yamada (Ed.), ISBN: 978-95351-0413-1, InTech, Available from: http://www.intechopen.com/books/tachycardia/surgical-maze-proceduresfor-atrial-arrhythmias-in-univentricular-hearts-from-maze-history-to-conver

\section{INTECH}

open science | open minds

\section{InTech Europe}

University Campus STeP Ri

Slavka Krautzeka 83/A

51000 Rijeka, Croatia

Phone: +385 (51) 770447

Fax: +385 (51) 686166

www.intechopen.com

\section{InTech China}

Unit 405, Office Block, Hotel Equatorial Shanghai

No.65, Yan An Road (West), Shanghai, 200040, China

中国上海市延安西路65号上海国际贵都大饭店办公楼405单元

Phone: +86-21-62489820

Fax: +86-21-62489821 
(C) 2012 The Author(s). Licensee IntechOpen. This is an open access article distributed under the terms of the Creative Commons Attribution 3.0 License, which permits unrestricted use, distribution, and reproduction in any medium, provided the original work is properly cited. 